\title{
How to Effectively Use Body Language
}

\section{COMMUNICATION CORNER NO. 33}

\author{
by Philip Yaffe
}

\section{Editor's Introduction}

Each "Communication Corner" essay is self-contained; however, they build on each other. For best results, before reading this essay and doing the exercise, go to the first essay "How an Ugly Duckling Became a Swan," then read each succeeding essay.

Learn how to use body language when delivering a speech or presentation. This installment of Communication Corner presents the practical aspects of body language such as eye contact, gestures, and vocal intonation to name a few. 


\title{
How to Effectively Use Body Language
}

\author{
COMMUNICATION CORNER No. 33
}

\section{by Philip Yaffe}

Some people claim how you deliver a speech is much more important than what you actually say, in particular "body language." This is nonsense. If your objective is to convey important information and ideas, or to convince people to consider and adopt your point of view, words are crucial. No matter how effectively you employ your body, if people can't easily understand and assimilate what you are saying, your effort is useless.

This can easily be demonstrated. Many great orators of the early to mid-20th century moved audiences - and indeed changed the course of history-via radio, where body language was not an option.

This is not to say the various elements of body language are not important, but they should be kept in proportion; otherwise, they can become seriously detrimental.

For example, some speakers regularly pace back and forth in front of an audience because they believe movement attracts and holds the audience's attention. Indeed, it does. However, when movement is mechanical and as predictable as a metronome, it has exactly the opposite effect. Likewise, speakers who mechanically wave their hands around or constantly shift their weight from one foot to the other are making the same mistake.

The true purpose of body language is not to focus attention on the speaker, but to emphasize what they are saying. Movements that take on a life of their own are counterproductive.

So what should be the proportion between words and movement in a successful oral presentation? This question has no answer, because it makes no sense. It all depends on what the speaker is saying and what kind of response they seek to achieve.

Perhaps the best overall advice on the subject comes from Toastmasters International, the worldwide club (not a school) devoted to improving public speaking. In their manual for members (some 360,000 individuals across 145 countries), they say:

Body language should look natural and unrehearsed, and be consistent with the words being spoken. Using body language that is comfortable for you and enjoyable for your audience takes thought and practice. 
After you have drafted your speech, read it and note any places where body language would be appropriate and help convey your message. Try several different ways of using your arms, hands, and facial expressions. Match your gestures to your words. You should be compelled to gesture and make facial expressions when your thought requires such action.

In short, body language must complement and reinforce your words, never overpower them.

With this theoretical framework in mind, let's look at some of the practical aspects of body language.

\section{Eye Contact}

The first thing on virtually everyone's list of body language components is eye contact. This is because if you can make some kind of personal bond with your audience, i.e. if they feel that they are being recognized as individuals, they will pay closer attention and give greater credence to what you are saying.

Many novice speakers seem to want to look anywhere but at the audience, e.g. at the floor, the ceiling, the walls, their notes, their hands. When they do look at the audience, it is almost as if they are looking at an amorphous blob, or right through them as if they weren't even there.

It is not enough to just regularly gaze around the room as if your head were on a swivel. Each time you move you gaze, try to focus on a single individual listener. Look them directly in the eyes for 5-10 seconds. The larger the audience, the less apparent it will be at who you are looking, but this doesn't matter. The important thing is to look at them as individuals, not as a group.

\section{Facial Expressions}

Express emotion with facial expressions. If you are pleased by something, smile. If you are disturbed by something, look perplexed. If you are calling the audience to action, show determination. In short, whatever you are feeling, try to inscribe it on your face. In principle, your words and tone of voice should be enough; however, emphasis shown by an appropriate facial expression can significantly boost the effect.

\section{Unconscious Gestures}

Unconscious gestures are those you do without being aware of them. They are perhaps best described as "distracting mannerisms." Since they add nothing to your presentation, they can only detract from it. Unconscious gestures include such things as fidgeting, twitching, lip biting, key jingling, hands in the pockets or behind the back, etc. 
Such distracting gestures are difficult to overcome by yourself because they are unconscious; you are not aware that you are doing them. A good way to overcome them is to videotape yourself while you are practicing a speech. Another way is to have a friend observe you while you are practicing a speech.

Perhaps the best way is to join a self-help group such as Toastmasters International. Some distracting mannerisms may not reveal themselves during a practice session, but only when you are in front of an audience. Noting and helping members overcome these distracting mannerisms in front of a live audience is integral to what Toastmaster meetings are all about.

\section{Conscious Gestures}

Conscious gestures are those that you use deliberately because they add energy and increase the impact of your presentation. The number of such gestures is almost limitless. As Toastmasters advises, the key thing is that your gestures should match your words. You should be compelled to gesture and make facial expressions when your thought requires such action.

For example, counting off a series of items on your fingers; holding your hands apart to show height or length; or drawing a square, a circle, a triangle in the air with your hands to show the shape of something, etc.

On occasion, you may also wish to use your entire body. For example:

- When you want to emphasize something, take a step or two toward the audience, which suggests that you are taking them into your confidence.

- When you have completed one section of your presentation and want to start on the next, take a couple of steps to the left or right of the speaking area. Ideally, this maneuver should be made without speaking. The two or three seconds of silence necessary for the movement is a clear signal to the audience that an important change in the presentation is about to take place.

The number of ways you can effectively use your body to reinforce your words is virtually endless. But at all times, bear in mind that reinforcing your words is the overriding purpose of body language. You should be compelled to make such gestures because your words call for them. Otherwise, leave them alone.

\section{How to Effectively Use Vocal Variety}

Have you ever read a text where virtually every sentence contained at least one word in italics, or one word underlined, or double underlined? And virtually every sentence was punctuated 
with an exclamation mark, or two exclamation marks, or even three exclamation marks? If you have, chances are you didn't read much of it.

It is the writer's craft (it is not an art) to make their appeal by the words they choose and how they weave them into clear, concise, logically structured sentences and paragraphs. Weighing down writing with such obvious attention-soliciting artifices as double underlining and multiple exclamation marks not only betrays the writer's lack of skill, it is seriously counterproductive.

On the other hand, a speech delivered without analogous oral artifices is equally counterproductive because most listeners are likely to find it dull, tedious, and soporific.

Why this dichotomy?

Fundamentally, it is because with a text, the reader sets the environment and controls the flow of information. With a speech, the listener controls nothing; they are dependent on the speaker.

Oral artifices employed to guide the listener's attention come under the heading "vocal variety." They are used to emphasize key words and phrases by raising and lowering the volume of the voice, raising and lowering the pitch of the voice, emphasizing and de-emphasizing specific words. And often by apparently doing nothing at all, i.e. pausing.

Judicious use of vocal variety ensures listeners receive each point of emphasis and nuance that otherwise would go by too quickly for them to capture and analyze it. Moreover, the use of vocal variety is entertaining.

However, we must be careful not to go to extremes. Each vocal variety artifice must be used for a purpose-and that purpose must be to help the listener glean as much as possible from the presentation as quickly and agreeably as possible. And in particular, to ensure the key ideas of the presentation will be understood and retained days, weeks, and even months later.

To achieve this objective, you should build in vocal variety as you prepare your oral presentation.

It is usually preferable not to do this in the first draft, which should be dedicated to getting down all your relevant information in reasonably comprehensible form. Starting from the second draft (all oral presentations require at least two drafts), look for places where vocal variety could help your cause, and then clearly mark them.

The four principal types of vocal variety you will want to consider are: 
1. Pace. One of the easiest ways to give emphasis to a phrase or a sentence is simply to slow down from your normal pace as you say it. Listeners can't help but notice that a change is taking place, so they pay closer attention.

2. Pitch. Use pitch to help convey different emotions. A sad voice will have a different pitch than a happy one; an excited voice will have a different pitch than a bored one, etc.

3. Volume. Volume (loudness) is also a good way to express emotions. A sad voice will have a different volume than a happy one; an excited voice will have a different volume than a bored one, etc.

4. Pause. The simple pause (1-3 seconds of silence) is perhaps the most overlooked-and therefore most underused-form of vocal variety. It is also one of the most important. As all professional entertainers know, not saying something (timing) often speaks volumes.

\begin{abstract}
About the Author
Philip Yaffe was born in Boston, Massachusetts, in 1942 and grew up in Los Angeles, where he graduated from the University of California with a degree in mathematics and physics. In his senior year, he was also editor-in-chief of the Daily Bruin, UCLA's daily student newspaper. He has more than 40 years of experience in journalism and international marketing communication. At various points in his career, he has been a teacher of journalism, a reporter/feature writer with The Wall Street Journal, an account executive with a major international press relations agency, European marketing communication director with two major international companies, and a founding partner of a specialized marketing communication agency in Brussels, Belgium, where he has lived since 1974. He is the author of more than 30 books, which can be found easily in Amazon Kindle.
\end{abstract}

DOI: $10.1145 / 3447263$ 